\title{
Structure and Maintenance Mechanisms of the Mascarene High in Austral Winter
}

\author{
Yuan Zhao
}

Sun Yat-Sen University

\section{Zhiping Wen}

Fudan University

Xiuzhen Li ( $\boldsymbol{\nabla}$ lixiuzhen@mail.sysu.edu.cn )

Sun Yat-Sen University https://orcid.org/0000-0002-4672-0455

\section{Ruidan Chen}

Sun Yat-Sen University

\section{Guixing Chen}

Sun Yat-Sen University

\section{Research Article}

Keywords: Maintenance mechanisms, Mascarene High, Diabatic heating, Static stability, Friction dissipation

Posted Date: July 14th, 2021

DOl: https://doi.org/10.21203/rs.3.rs-708688/v1

License: (c) (i) This work is licensed under a Creative Commons Attribution 4.0 International License. Read Full License

Version of Record: A version of this preprint was published at International Journal of Climatology on December 15th, 2021. See the published version at https://doi.org/10.1002/joc.7498. 


\section{Structure and Maintenance Mechanisms of the Mascarene High in Austral Winter}

Yuan Zhao ${ }^{1}$, Zhiping Wen ${ }^{2,3}$, Xiuzhen Li $^{1,4,5,3^{*}}$, Ruidan Chen ${ }^{1,4,5,3}$, Guixing Chen ${ }^{1,4,5}$

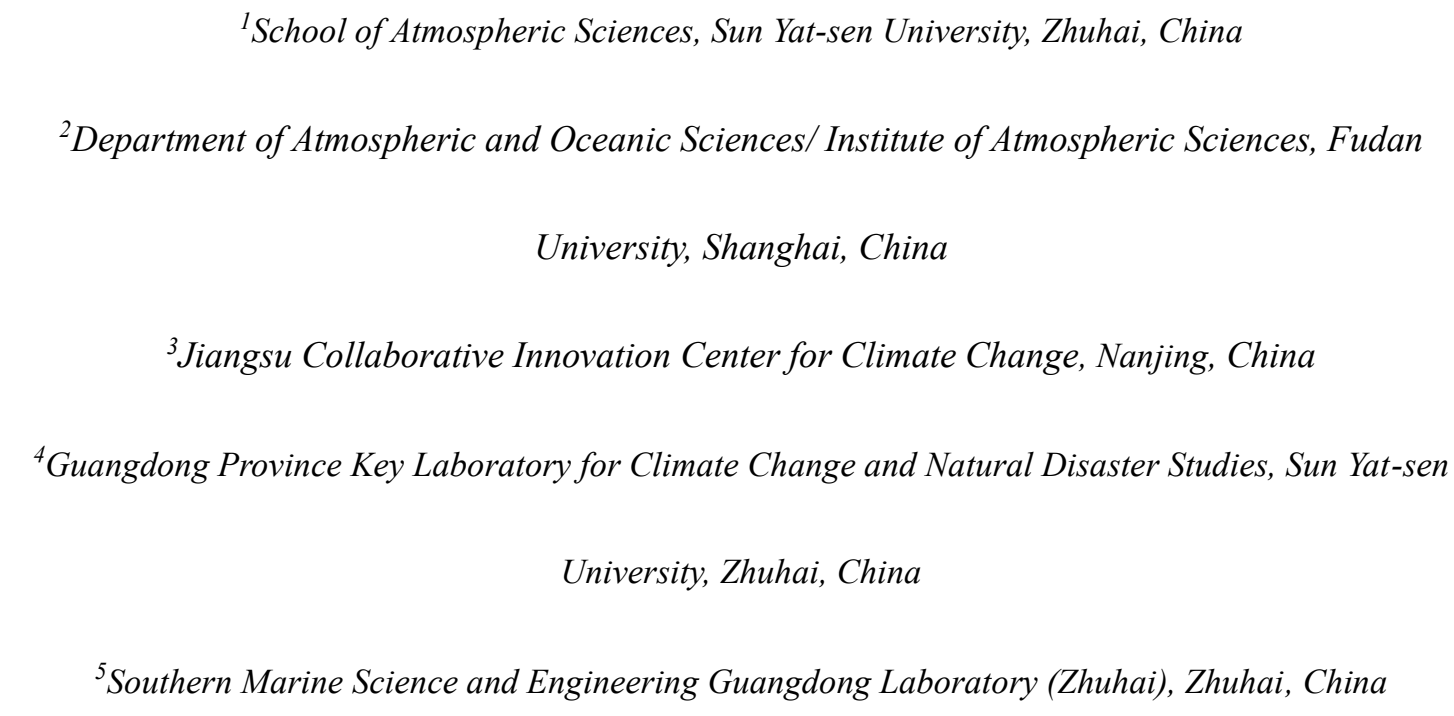

Corresponding author:

Xiuzhen Li

School of Atmospheric Sciences Sun Yat-sen University

Zhuhai 519082

China

E-mail: lixiuzhen@mail.sysu.edu.cn 


\section{Abstract}

The Mascarene High (MH), is a key component of the Asian-Africa-Australia monsoon system in austral winter (JJA). Its three-dimensional structures and maintenance mechanisms are examined in this study. It is a low-level subtropical high dominating the southern Africa and South Indian Ocean, characterized by a northwestward tilt with height, which is attributed to its spatially inhomogeneous thermal structure. Large-scale subsidence characterizes the main body of the $\mathrm{MH}$, with the stronger subsidence to the east than to the west.

Diagnosis using the complete form of the vertical vorticity tendency equation shows that the anticyclonic structure of the $\mathrm{MH}$, which can be described by the distribution of meridional wind, is maintained mainly by the vertical gradient of diabatic heating, change in static stability, and friction dissipation. In particular, a combination of sensible heating and longwave radiative cooling results in a vertical decreasing gradient of diabatic heating in the lower troposphere. It generates the stronger southerlies over the subtropical South Indian Ocean than over the southern Africa. Meanwhile, over the South Indian Ocean, the increasing static stability as a result of the downward transport of a more stable atmosphere partly offsets the effect of the vertical gradient of diabatic heating, and southerlies still prevail there. Over the southern Africa, topographic friction dissipation induces northerlies, balancing the effect of the vertical gradient of diabatic heating with a stronger magnitude, and northerlies prevail.

Keywords: Maintenance mechanisms, Mascarene High, Diabatic heating, Static 
stability, Friction dissipation 


\section{Introduction}

The Mascarene High (MH), also termed the southern Indian Ocean subtropical high, is a high-pressure area embedded in the austral subtropical high-pressure belt throughout the year. It can trigger the Indian Ocean Subtropical Dipole (IOSD) through surface heat flux and wind speed anomalies (Behera and Yamagata 2001; Morioka et al. 2010; Morioka et al. 2012) and plays an important role in modulating the rainfall over southern Africa by importing moisture from the South Indian Ocean (Harrison 1984; Manatsa et al. 2014; Cook 2000). More importantly, as a major member of the Asian summer monsoon system during austral winter (JJA, Krishnamurti and Bhalme 1976), the MH can also modulate the Indian summer monsoon and thus the precipitation over East Asia, with its outflow crossing the equator over the western Indian Ocean and then veering toward South Asia (Xue et al. 2004; Han et al. 2017). Hence, it is of great importance to improve our knowledge about the activity of the $\mathrm{MH}$ in austral winter.

Because of the lack of observations over oceans, circulation characteristics over the Southern Hemisphere cannot be clearly disclosed unless satellite data are employed. The features and mechanisms of austral systems are usually disclosed by examining the consistency and difference with their counterparts in the Northern Hemisphere. In the Northern Hemisphere, surface subtropical anticyclones reside over the eastern portions of the subtropical ocean basins throughout the year and show a strong seasonal variability in intensity and meridional location - that is, the highest intensity and northernmost location occur in summer. The vertical motion inside the subtropical 
highs is diverse, characterized by strong subsidence over the eastern portion and ascending motion to the west in summer (Miyasaka and Nakamura 2005, 2010; Wu et al. 2009). The axis of the subtropical high tends to tilt toward the warm sector, that is, equatorward and westward with height based on the geostrophic relationship. However, the MH exhibits a seasonality distinct from its counterpart in the Northern Hemisphere and other ocean basins. It resides over the eastern part of the South Indian Ocean in austral summer, while it strengthens and shifts westward in winter, covering the southern Africa and the South Indian Ocean (Miyasaka and Nakamura 2005; Miyamoto et al. 2018; Vidya et al. 2020). As a result, whether the spatial and thermal structures of the $\mathrm{MH}$ in austral winter, such as vertical motion and axis displacement, show features similar or opposite to its counterpart in boreal summer in the Northern Hemisphere remains unknown.

Traditionally, subtropical highs are regarded as a result of a sinking branch of the Hadley circulation. However, the stronger subtropical highs observed in summer seem to conflict with this argument, as the zonally symmetric Hadley circulation predicts much weaker subtropical subsidence in summer (Hoskins 1996). Hence, the theory of the Hadley circulation does not seem to fully explain the existence of subtropical highs (Hoskins 1996; Rodwell and Hoskins 2001; Liu et al. 2001; Li et al. 2019; Li et al. 2020). Further studies have shown that subtropical cell-type high-pressure systems instead of a zonally uniform high-pressure belt are detected over subtropical regions, as a manifestation of climatological summertime stationary waves maintained by global diabatic heating (Ting 1994), especially monsoonal heating (Hoskins and Rodwell 1995; 
Rodwell and Hoskins 1996; Chen et al. 2001). Rodwell and Hoskins (2001) further concluded that the combined effects of topography and monsoonal heating to the east are of primary importance for the formation of surface subtropical highs and subsidence aloft, with reinforcement by local cooling over the eastern ocean.

By simplifying the vorticity equation, Wu and Liu (1999) further emphasized the crucial role of vertical inhomogeneity in diabatic heating (Liu et al. 2001; Liu et al. 2004; Wu and Liu 2003; Wu et al. 1999; Liu et al. 1999a; Liu et al. 1999b). Further studies by Wu and Liu (2003) and Liu et al. (2004) proposed a summertime subtropical quadruple heating pattern and illustrated the key role of vertical increases (decreases) in diabatic heating in motivating the poleward (equatorward) flow underneath in both hemispheres. In contrast, Miyasaka and Nakamura $(2005,2010)$ emphasized that the near-surface thermal contrast between ocean and land could accurately reproduce summertime subtropical highs in their modeling study, and the local positive feedback between low-level longwave radiative cooling, subtropical highs, and marine stratus cloud over the eastern ocean could play an important role in maintaining summertime subtropical highs (Klein and Hartmann 1993; Wu et al. 2009; Norris 1998; Norris and Klein 2000). Furthermore, a study by Lee et al. (2013) highlighted the interhemispheric influence of northern summer monsoons on southern subtropical anticyclones. Enhanced summer monsoonal convection produces subsidence over the Southern Hemisphere via interhemispheric meridional overturning circulation and increases sea level pressure locally and remotely by motivating stationary barotropic Rossby waves. Hence, the formation and maintenance of the subtropical highs are complicated. 
110 Previous studies have widely investigated the mechanisms of the summertime

111 subtropical high, especially in the Northern Hemisphere. However, the maintenance

112 mechanism of the $\mathrm{MH}$ in the southern Indian Ocean and the relative importance of the

113 different processes involved have not been fully understood and deserve more attention.

114 This study aims to investigate the spatial structure and maintenance mechanisms

115 of the wintertime $\mathrm{MH}$, with emphasis on the relative importance of different physical

116 processes in its maintenance. The causes of the key processes will be investigated in

117 detail. The rest of this paper is organized as follows. In section 2, the data and methods

118 applied in this study are presented. The climatological dynamic and thermal structure

119 of the $\mathrm{MH}$ are analyzed in section 3. The maintenance mechanisms of the MH are

120 demonstrated in section 4 , focusing on the physical processes associated with external

121 and internal forcing. Conclusions and discussion follow in section 5.

\section{$122 \quad 2$ Data and methods}

\subsection{Data} Japanese 55-year Reanalysis (JRA-55), the global reanalysis constructed by the Japan Meteorological Agency (JMA; Kobayashi et al. 2015; Harada et al. 2016), from 1979 to 2017 , with a horizontal resolution of $1.25^{\circ}$ longitude $\mathrm{x} 1.25^{\circ}$ latitude. This data set extends from $1000 \mathrm{hPa}$ to $1 \mathrm{hPa}$, with 37 vertical pressure levels. Compared with other reanalysis data, JRA-55 has improved the representation of climate variability in the tropics and the temporal consistency throughout the reanalysis period (Chen et al. 2014;

131 Harada et al. 2016). The variables employed in this study are geopotential height, 
horizontal wind fields, temperature, and vertical velocity. Monthly heating rate data are also used to investigate the horizontal and vertical distributions of diabatic heating. Furthermore, we also used monthly mean reanalysis data extracted from the National Centers for Environmental Prediction (NCEP)/Department of Energy (DOE) Reanalysis 2 (NCEP-2) and the European Centre for Medium-Range Weather Forecasts (ECMWF) Interim Reanalysis Data (ERA-Interim) to verify the major features. The austral winter is defined as the mean of June-August (JJA).

\subsection{Methods}

In previous studies (Liu et al. 2001; Liu et al. 2004; Wu et al. 1999; Liu et al. 1999a; b), the complete form of the vertical vorticity tendency equation has proven to be a powerful tool to diagnose the formation and maintenance mechanisms of subtropical anticyclones. The specific information on the derivation of the equation is provided in appendix. Deduced from the Ertel potential vorticity theory, the equation can be written as:

$$
\begin{aligned}
& \frac{\partial \zeta}{\partial t}+\vec{V} \cdot \nabla \zeta+\beta v=(1-K)(f+\zeta) \frac{\omega}{P}-(f+\zeta) \frac{1}{\theta} \frac{d \theta}{d t}+\frac{1}{\theta_{z}} \overrightarrow{F_{\zeta}} \cdot \nabla \theta+\frac{f+\zeta}{\theta_{z}} \frac{\partial Q}{\partial z}-\frac{1}{\theta_{z}} \frac{\partial v}{\partial z} \frac{\partial Q}{\partial x} \\
& \text { V1 V2 } \\
& \text { V3 } \\
& \text { V4 } \\
& \text { V5 } \\
& \text { V6 } \\
& +\frac{1}{\theta_{z}} \frac{\partial u}{\partial z} \frac{\partial Q}{\partial y}+\frac{1}{\alpha} P_{E} \frac{d}{d t}\left(\frac{1}{\theta_{z}}\right)-\frac{1}{\alpha} \frac{d}{d t}\left(C_{D}\right) \\
& \text { V8 } \\
& \text { V9 } \\
& \text { V10 }
\end{aligned}
$$

where $\zeta$ denotes relative vertical vorticity, $f$ is the Coriolis parameter, and $\beta=\frac{\partial f}{\partial y}$. $P$ represents the air pressure. $K=R / C p, R$ and $C p$ are the gas constant and specific heat capacity in dry air at constant pressure. $Q$ and $\theta$ are the diabatic heating rate and potential temperature, respectively. $\theta_{z}=\frac{\partial \theta}{\partial z}$ is static stability, $\overrightarrow{F_{\zeta}}$ and $P_{E}$ are frictional 
dissipation and potential vorticity. $C_{D}$ is a thermodynamic parameter. On the left-hand side, the first term is the vertical vorticity tendency, which is negligible from a longterm perspective, and the other two terms are the advections of relative vorticity (V1) and geostrophic vorticity (V2). The first term on the right-hand side is the effects of vertical velocity (V3). Based on the thermodynamic energy equation, the second term represents the effect of diabatic heating itself (V4). The next four terms on the righthand side are the frictional dissipation effect (V5), and the influence of non-uniform diabatic heating in the vertical (V6), zonal (V7), and meridional (V8) directions. The last two terms are the effect of the Lagrangian time rate of change in static stability (V9, change in static stability hereafter), and the mapping from horizontal vorticity components to vertical vorticity components due to the tilt of the isentropic surface (V10); both represent changes in the internal thermodynamic structure of the atmosphere (Wu and Liu 1999; Wu 2001). Hence, by applying the complete form of the vertical vorticity tendency equation, the relative contributions of dynamical and themodynamical processes to the tendency of vertical vorticity can be evaluated.

Previous studies have confirmed that the formation and maintenance of subtropical highs are attributed mainly to spatial inhomogeneity in diabatic heating (Rodwell and Hoskins 2001; Wu and Liu 2003; Liu et al. 2001; Liu et al. 2004). In this study, we use the apparent heat source $Q$ to analyze the diabatic heating associated with the maintenance of the $\mathrm{MH}$ in the complete form of the vertical vorticity tendency equation, which is computed as a residual in the thermodynamic equation by referring to Yanai et al. (1973) and Luo and Yanai (1984): 


$$
Q=C_{p}\left[\frac{\partial T}{\partial t}+\vec{V} \cdot \nabla T+\left(\frac{p}{p_{0}}\right)^{K} \omega \frac{\partial \theta}{\partial p}\right]
$$

where $T$ is temperature, $\theta$ is potential temperature; $\vec{V}$ is horizontal velocity; $\omega$ is vertical velocity; $K=R / C_{p}, R$ and $C_{p}$ are the gas constant and specific heat capacity in dry air at constant pressure; and $p_{0}=1000 \mathrm{hPa}$. To further compare the contributions of different types of diabatic heating, the latent heating rate ( $\mathrm{LH}$; which includes the convective heating rate and large-scale condensation heating rate), sensible heating rate ( $\mathrm{SH}$; also termed the vertical diffusion heating rate), and radiative heating rate $(\mathrm{RH})$ derived from JRA-55 are also employed.

It should be noted with caution that $Q$ computed as a residual in the thermodynamic equation instead of the total heating rate $\left(Q_{T}=L H+S H+R H\right)$ derived from JRA-55 is preferred in the calculation of V6-8 in equation 1 for better equation closure. In fact, the apparent heat source $(Q)$ shows high consistency with the total heating rate $\left(Q_{T}\right)$ in spatial distribution, but with a slightly smaller magnitude (not shown).

\section{Dynamic and thermal structures of the Mascarene High}

To depict the spatial structures of the MH, Figure 1 shows the climatology of wintertime geopotential height along with horizontal wind fields from near the surface to $500 \mathrm{hPa}$ over the South Indian Ocean. Clearly, the MH is a cell-type anticyclonic high-pressure system with a well-defined core region, constrained in the lower troposphere below $700 \mathrm{hPa}$. Its activity center lies over the western South Indian Ocean at around $30^{\circ} \mathrm{S}$ near the surface, with its outflow rotating anticyclonically. The southeasterly flow north to the $\mathrm{MH}$ is strong in the lower troposphere and will move 
across the equator and act as an important source of the South Asian summer monsoon.

The activity center of the MH tilts northwestward with height, with two split centers lying over the southern Africa and the western South Indian Ocean at $850 \mathrm{hPa}$, and one core over the southern Africa at around $20^{\circ} \mathrm{S}$ at $700 \mathrm{hPa}$. At $500 \mathrm{hPa}$, it transforms into a zonally uniform belt across the subtropical region, with strong westerlies prevailing to the south.

The vertical tilt of the MH may be related to its thermal structure. To clarify this issue, the vertical distribution of temperature along with geopotential height in both the meridional and zonal directions is examined. The meridional-vertical sections of temperature along with the geopotential height deviation from the equatorial value averaged between $20^{\circ}$ and $110^{\circ} \mathrm{E}$ are shown in Fig. 2a. The geopotential height characterized by a subtropical high-pressure center is detected only in the lower troposphere below $700 \mathrm{hPa}$, consistent with the result shown in Fig. 1. The MH tilts slightly equatorward with height to the high-temperature region in low latitudes. This is consistent with other subtropical highs characterized by an axis tilting toward the warm sector with height. A zonal-vertical section of the zonal deviation of temperature and geopotential height averaged between $20^{\circ}$ and $35^{\circ} \mathrm{S}$ is shown in Fig. 2b. The deviation of geopotential height is zonally standardized so that the values at different levels are comparable. A positive zonal deviation of geopotential height is observed between $20^{\circ}$ and $60^{\circ} \mathrm{E}$, indicating the location of the $\mathrm{MH}$ center over the southern Africa and the western South Indian Ocean in the lower troposphere. In the upper troposphere, though the cell-type anticyclone is deformed into a zonal belt, a ridge can still be found 
overlying the $\mathrm{MH}$. Together, a large zonal deviation in temperature is found in the lower troposphere, reflecting a strong land-sea thermal contrast, with higher temperature over the southern Africa and Madagascar and lower temperature over the subtropical South Indian Ocean basin. The zonal deviation of temperature overturns at around $60^{\circ} \mathrm{E}$. As a result, the center of the MH tilts westward with height to the higher temperature over the land region in the lower troposphere. In the upper level, an opposite zonal gradient of temperature is found, which might be why the upper ridge tilts eastward with height (Fig. 2b).

To further explore the dynamic structure of the $\mathrm{MH}$, the vertical motion associated with the subtropical high over the South Indian Ocean is examined (Fig. 3a). Largescale subsidence characterizes the main body of the $\mathrm{MH}$, with the strongest subsidence east of the southern Africa and the central South Indian Ocean, respectively. That is, the maximum subsidence lies east of the centers of the MH depicted by the geopotential height and wind fields. Such a double-center structure of descending motion might be attributed to the zonal inhomogeneity of the local meridional circulation expanding between tropics and subtropics. As is shown in Figs. 3b-3c, two local meridional circulation cells with their descending branches over the western $\left(20^{\circ}-50^{\circ} \mathrm{E}\right)$ and eastern $\left(60^{\circ}-110^{\circ} \mathrm{E}\right)$ parts of the $\mathrm{MH}$ are distinct from each other. In the western part, a typical double-loop structure over the Southern and Northern Hemispheres are detected, characterized by tropical ascending motion associated with North African monsoonal heating $\left(0^{\circ}-20^{\circ} \mathrm{N}\right)$ and two subtropical descending branches off the equator (Fig. 3b). The equatorial ascent is much weaker than the subtropical descent, illustrating that the 
meridional circulation might play only a partial role in the subsidence over the western MH. Instead, over the eastern part of the $\mathrm{MH}$, the meridional circulation is a single loop, characterized by strong ascending motion over the equator and subtropical Northern Hemisphere and descending motion over the subtropical Southern Hemisphere (Fig. 2c). Such a strong meridional circulation is triggered by South Asian monsoonal convective heating, the strongest global heating source. As Lee et al. (2013) point out, the boreal summer monsoonal convection plays an important role in either maintaining or strengthening the southern subtropical anticyclones via interhemispheric meridional overturning circulations. Hence, zonal asymmetry appears in the dynamic structure of the $\mathrm{MH}$, which might imply a zonal asymmetry in the maintenance of the $\mathrm{MH}$; this will be discussed in detail in section 4 .

A comparison based on JRA-55, NCEP-2, and ERA-Interim shows quite similar spatial distributions of the MH (not shown), indicating that the conclusions associated with the characteristics of the MH in JRA-55 are reliable. In summary, the MH shows spatial inhomogeneity in dynamic and thermal conditions, with its ridge tilting equatorward and westward with height to a warmer section. The west-to-east discrepancy in the equator-subtropics meridional circulation cell associated with the $\mathrm{MH}$ indicates that different processes might be occurring in its maintenance dynamics.

\section{Maintenance mechanisms of the Mascarene High}

\subsection{Physical processes involved in maintaining the Mascarene High}

The complete form of the vertical vorticity tendency equation (Equation 1) is a preferable tool for diagnosing the formation and maintenance mechanisms of the $\mathrm{MH}$, 
as it includes not only dynamic elements but also external and internal forcings (Liu et al. 2001; Wu and Liu 1999; Wu 2001). The spatial distributions of the different physical processes involved in the vertical vorticity tendency equation at $850 \mathrm{hPa}$ are shown in Fig. 4. The level of $850 \mathrm{hPa}$ is selected because the $\mathrm{MH}$ is strong at this level and its outflow plays an important role in the Asian summer monsoon. Because it is the maintenance of the climatological mean of the $\mathrm{MH}$ that is being examined, the tendency is, the change in vorticity is controlled mainly by the advection of geostrophic vorticity

$(\beta v)$, and it is balanced by difference physical processes on the right-hand side of Equation 1, which is consistent with Wu et al. (1999). The advection of geostrophic vorticity is the change in the relative vorticity caused by the geostrophic vorticity transported by meridional winds. As an anticyclonic circulation system instead of a zonally uniform high-pressure belt, the most prominent feature of the $\mathrm{MH}$ is the meridional wind shear in a zonal orientation. In other words, the distribution of the anticyclonic $\mathrm{MH}$ can be represented by the horizontal displacement of meridional winds, and its center can be observed at the transition between the southerlies and northerlies. Hence, the maintenance of the anticyclonic structure of the MH can be explored by studying the maintenance of $\beta v$ instead. In Fig. $4 \mathrm{~b}$, the distribution of $\beta v$ over the subtropical South Indian Ocean shows a west-to-east dipole pattern. Negative $\beta v$ is detected over the southern African continent and Madagascar, corresponding to the northerlies on the western side of the MH anticyclone, while widespread positive $\beta v$ 
covers the subtropical South Indian Ocean where southerlies prevail (Fig. 1c).

As is shown in Figs. $4 \mathrm{c}-4 \mathrm{j}$, of the eight terms on the right-hand side of the complete form of the vertical vorticity tendency equation, the magnitudes of the frictional dissipation (V5), vertical gradient of diabatic heating (V6), and change in static stability (V9) are much larger than those of the other terms over the region where the MH lies. The effect of vertical velocity (V3) and heating itself (V4), the horizontal gradient of diabatic heating (V7-V8), and the mapping from horizontal vorticity components to vertical vorticity components (V10) are around one order smaller and are negligible in the maintenance of the MH. Hence, by applying the scale analysis technique, Equation 1 can be simplified as:

$$
\beta v \approx \frac{1}{\theta_{z}} \overrightarrow{F_{\zeta}} \cdot \nabla \theta+\frac{f+\zeta}{\theta_{z}} \frac{\partial Q}{\partial z}+\frac{1}{\alpha} P_{E} \frac{d}{d t}\left(\frac{1}{\theta_{z}}\right)
$$

$$
\begin{array}{llll}
\mathrm{V} 2 & \mathrm{~V} 5 & \mathrm{~V} 6 & \mathrm{~V} 9
\end{array}
$$

In Equation $3, \beta v$ can be regarded as the joint result of the vertical gradient of diabatic heating, frictional dissipation, and change in static stability. This is different from the simple Sverdrup balance in Liu et al. (2004), in which only the effect of the vertical gradient of diabatic heating is emphasized when the maintenance of the western Pacific subtropical high is studied, based on the premise that frictional dissipation and the role of changes in the internal thermodynamic structure of the atmosphere are negligible. However, in this study focusing on the MH over the southern Africa and the subtropical South Indian Ocean, these two terms are non-negligible, and their roles in maintaining the MH deserve more exploration.

As shown Fig. 4f, the vertical gradient of diabatic heating is positive and spatially 
uniform over the subtropical South Indian Ocean basin, with its center lying over the east-central subtropical South Indian Ocean. Positive values can also be found over the southern African continent. That is, the vertical gradient of diabatic heating contributes western and eastern parts of the MH. The spatial distribution of frictional dissipation (Fig. 4e) is large over the southern African continent due to the orographic effect, which positively to $\beta v$ and is favorable for the maintenance of southerlies over both the is negative and contributes to the maintenance of northerlies over the southern Africa, counteracting the effect of the vertical gradient of diabatic heating. Over the South Indian Ocean, the frictional dissipation is weak, and the effect of the vertical gradient of diabatic heating is offset mainly by the change in static stability (Fig. 4i). The change in static stability exhibits a zonally elongated negative center over the subtropical South Indian Ocean, similar to that of the vertical gradient of diabatic heating but with opposite sign. It is weak over the continent, which might be related to the weak static stability when the atmosphere is unstable. Hence, a west-to-east discrepancy over the southern Africa and the subtropical South Indian Ocean characterizes the maintenance of $\beta v$ and thus the structure of the $\mathrm{MH}$.

To show the west-to-east discrepancy more quantitatively, the regional mean of the key terms in Equation 3 is calculated over the southern Africa (continental region, $35^{\circ} \mathrm{S}-15^{\circ} \mathrm{S}, 15^{\circ} \mathrm{E}-35^{\circ} \mathrm{E}$ ), with prevailing northerlies on the western side of the $\mathrm{MH}$, and over the subtropical South Indian Ocean (ocean region, $35^{\circ} \mathrm{S}-15^{\circ} \mathrm{S}, 60^{\circ} \mathrm{E}-110^{\circ} \mathrm{E}$ ), with prevailing southerlies (Fig. 5). Over the continental region, negative $\beta v$ is the residual of the positive vertical gradient of diabatic heating $\left(\sim 1 \mathrm{e}^{-10}\right)$ and negative frictional 
dissipation $\left(\sim 1.8 \mathrm{e}^{-10}\right)$. That is, the northerlies over the southern Africa are maintained mainly by the balance of northerlies related to the potential effect of topographic friction or tropospheric mixing and the relatively weaker southerlies attributed to the vertical decrease in diabatic heating with height. In contrast, over the eastern side of the $\mathrm{MH}$, positive regional $\beta v$ is the residual of the vertical gradient of diabatic heating $(>2$ $\left.\mathrm{e}^{-10}\right)$ and the changes in static stability $\left(<-1.5 \mathrm{e}^{-10}\right)$, with the regional mean of frictional dissipation negligible in the troposphere. That is, the southerlies over the subtropical South Indian Ocean are stimulated by a strong vertical decrease in diabatic heating with height in the lower troposphere, which is partly offset by the change in static stability in the atmosphere. 
formation and maintenance of summertime subtropical anticyclones over both hemispheres has been proposed (Wu and Liu 2003; Liu et al. 2004). In the summertime, the eastern ocean is characterized by strong longwave radiative cooling, whereas the western and eastern continent are dominated mainly by sensible heating and convective heating, and the western ocean is characterized by two forms of dominant heating, with longwave radiative cooling prevailing over convective heating (Wu and Liu 2003). However, for the Southern Hemisphere and in the winter season, extremely strong monsoonal convective heating is absent, and the dominant diabatic heating pattern and its associated effects on the maintenance of subtropical highs might change.

To illustrate, a vertical-zonal section of different types of heating rates and their net effect-total heating rate averaged over $35^{\circ}-15^{\circ} \mathrm{S}$ are presented in Fig. 6 to examine their spatial distributions and relative importance. The total heating is large only in the lower troposphere, characterized by a strong vertical gradient. Diabatic heating is constrained near the surface and decreases with height to diabatic cooling above 850 $\mathrm{hPa}$, with its center detected over the subtropical South Indian Ocean at around $800 \mathrm{hPa}$ (Fig. 6a). Of the four different kinds of diabatic heating rates, because the magnitude of the solar radiative heating rate in the atmosphere is much smaller (not shown), only the characteristics of the sensible, latent, and longwave radiative heating rates are examined in Figs. 6b-6d, respectively. Clearly, the net diabatic heating near the surface is attributed mainly to sensible heating. It is positive and extends to around $700 \mathrm{hPa}$ over the southern African continent, with its maximum at around $850 \mathrm{hPa}$ due to the local high altitudes. In contrast, strong sensible heating can be found only near the 
surface and decreases abruptly with height over the subtropical South Indian Ocean. It turns into weak sensible cooling above $850 \mathrm{hPa}$. The diabatic cooling in the free atmosphere is contributed mainly by the longwave radiative cooling, the minimum of which lies over the subtropical South Indian Ocean at around $800 \mathrm{hPa}$. In contrast to the sensible heating and longwave radiative heating rate, the intensity of the latent heating rate is weaker over the region of interest; it acts as cooling near the surface and turns into heating with height over the subtropical South Indian Ocean.

Liu et al. (2004) and Wu and Liu (2003) have concluded that summer monsoonal convective heating to the east of continents in the upper troposphere plays an important role in the formation and maintenance of subtropical highs in the Northern Hemisphere, whereas latent heating in winter seems negligible over the southern Africa and the subtropical South Indian Ocean due to the absence of strong convection. In addition, the center of longwave radiative cooling is detected over the central South Indian Ocean instead of the eastern portion of the ocean, which might be related to westward displacement of the center of the MH in austral winter. This is different from the quadruple heating pattern, which maintains the seasonal peak of the subtropical high in the Northern Hemisphere in summer. Hence, the net diabatic heating within the MH is distinct and shows a negative vertical gradient in the lower troposphere as a combined result of sensible heating near the surface and longwave radiative cooling in the lower troposphere.

As mentioned above, though diabatic heating shows a decreasing trend with height over both the southern Africa and the South Indian Ocean, an apparent west-to-east 
discrepancy appears, and the contribution of the different kinds of heating are different in these two regions. To clarify, the vertical profiles of the regional average of the different kinds of heating rates over the southern Africa $\left(35^{\circ} \mathrm{S}-15^{\circ} \mathrm{S}, 15^{\circ} \mathrm{E}-35^{\circ} \mathrm{E}\right)$ and the subtropical South Indian Ocean $\left(35^{\circ} \mathrm{S}-15^{\circ} \mathrm{S}, 60^{\circ} \mathrm{E}-110^{\circ} \mathrm{E}\right)$ are shown in Fig. 7. Over the continent, because the precipitation over the southern Africa in winter is scarce, latent heating is negligible. The profile of the total diabatic heating is determined by sensible heating and longwave radiative cooling, which show a similar decreasing trend with height. As a result, the total diabatic heating is positive near the surface and decreases slightly with height; it becomes negative above $850 \mathrm{hPa}$ and reaches its minimum at around $700 \mathrm{hPa}$ (Fig. 7a). In contrast, latent heating is non-negligible over the subtropical South Indian Ocean. The total heating is determined by all three kinds of heating, transitioning from heating near the surface to cooling in the lower troposphere and reaching a minimum at around $800 \mathrm{hPa}$ (Fig. 7b). It shows a much sharper vertical decreasing trend in the lower troposphere than that over the southern Africa as a joint result of stronger decreasing trends in both sensible heating and longwave radiative cooling. The latent heating shows a contrary vertical profile, but it is weak and can only partly compensate for the other two kinds of heating. Hence, the vertical decreasing gradient of diabatic heating is much stronger over the ocean than over the continent.

As it was mentioned in section 4.1 that the effect of the vertical decrease in diabatic heating spanning from the southern Africa to the South Indian Ocean is favorable for the maintenance of southerlies, we will now explain its relevant mechanisms. Referring 
to Liu et al. (2001), considering the short-term evolution, in a statically stable atmosphere $\left(\theta_{z}>0\right)$ in the Southern Hemisphere $(f<0)$, the heating that decreases with height in the lower troposphere will generate a positive anticyclonic vorticity source as:

$$
\frac{\partial \zeta}{\partial t} \propto \frac{f+\zeta}{\theta_{z}} \frac{\partial Q}{\partial z}>0
$$

Thus, the vertical decreasing gradient of diabatic heating over the key region is conducive to triggering a low-level anticyclonic circulation in the short-term evolution. However, from a long-term evolution perspective, $\frac{\partial \zeta}{\partial t}$ can be negligible, and the geostrophic vorticity advection $(\beta v)$ from high latitudes by the southerlies can balance the positive vorticity source forced by diabatic heating following the Sverdrup balance (Wu et al. 1999; Liu et al. 1999a, b; Wu and Liu 2003; Liu et al. 2004). Hence, the vertical decrease in diabatic heating over the key region tends to generate southerlies in the long-term evolution, with that over the ocean larger than that over the continent.

\subsection{Change in static stability}

As it was shown in Figs. $4-5$ that a change in static stability plays an important role in the maintenance of the MH by offsetting the effect of the vertical gradient of diabatic heating over the subtropical South Indian Ocean, to further explore the physical processes involved in the change in static stability, it is decomposed as:

$$
\begin{aligned}
\frac{1}{\alpha} P_{E} \frac{d}{d t}\left(\frac{1}{\theta_{z}}\right) & =-\frac{1}{\alpha} P_{E}\left(\frac{1}{\theta_{z}{ }^{2}}\right) \frac{d \theta_{z}}{d t} \\
& =-\frac{1}{\alpha} P_{E}\left(\frac{1}{\theta_{z}{ }^{2}}\right)\left[\frac{\partial \theta_{z}}{\partial t}+\vec{V} \cdot\left(\nabla \theta_{z}\right)\right] \\
& =-\frac{1}{\alpha} P_{E}\left(\frac{1}{\theta_{z}{ }^{2}}\right)\left[\left(u \frac{\partial \theta_{z}}{\partial x}+v \frac{\partial \theta_{z}}{\partial y}\right)+w \frac{\partial \theta_{z}}{\partial z}\right]
\end{aligned}
$$

The change in static stability (Lagrangian time derivative of $\theta_{z}$ ) can be decomposed into the time rate of change of $\theta_{z}$ and the three-dimensional advection of $\theta_{z}$ (denoted by $\partial \theta_{z}$ 
$/ \partial t$ and $\left.\vec{V} \cdot \nabla \theta_{z}\right)$. Considering the long-term evolution, the local tendency of $\theta_{z}$ can be negligible, and the change in static stability is determined by the advection of static stability. The advection of $\theta_{z}$ can further be divided into horizontal advection $\left(u \frac{\partial \theta_{z}}{\partial x}+\right.$ $\left.v \frac{\partial \theta_{z}}{\partial y}\right)$ and vertical advection $\left(w \frac{\partial \theta_{z}}{\partial z}\right)$, which are caused by the spatially inhomogeneous distribution of static stability and atmospheric motion. Fig. 8 shows the distribution of the change in static stability and its vertical and horizontal advection components. The spatial distribution of the change in static stability is characterized by a widespread and relatively uniform negative value over the subtropical South Indian Ocean. That is, the static stability decreases with time over the ocean, which plays an important role in the maintenance of the $\mathrm{MH}$ as discussed in section 4.1. It is dominated by the vertical advection of $\theta_{z}$. In contrast, the scattered distribution of the change in static stability over the southern Africa, which has a negligible effect on $\beta v$, is caused mainly by the weak horizontal advection of $\theta_{z}$. Furthermore, scale analysis reveals that though the magnitude of vertical velocity $\left(w, \mathrm{e}^{-1}\right)$ in Equation 5 is an order less than the horizontal wind velocity $(u, v)$, the vertical gradient of static stability $\left(\frac{\partial \theta_{z}}{\partial z}\right)$ with an order of $\mathrm{e}^{-6}$ is much larger than the horizontal gradient $\left(\frac{\partial \theta_{z}}{\partial x}, \frac{\partial \theta_{z}}{\partial y}\right)$ with orders of $\mathrm{e}^{-10} \sim \mathrm{e}^{-11}$. Hence, the vertical advection of static stability is much larger than the horizontal advection; that is, the change in static stability is caused mainly by the vertical advection of static stability. Furthermore, the vertical velocity and vertical gradient of static stability at 850 hPa are shown in Fig. 9. The widespread subsidence and positive vertical gradient of static stability are detected over the subtropical South Indian Ocean with similar spatial distribution. That is, the static stability increases with height in the lower troposphere 
where descending motion dominates. As was shown in Fig. 3c, the descending branch of the interhemispheric meridional overturning circulation is induced by strong monsoonal convection over South Asia (Lee et al. 2013). Hence, air with higher static stability is transported downward to lower static stability surroundings over the subtropical South Indian Ocean, and the static stability of the air parcels is decreased, further maintaining the MH. Here, two questions remain: Why is the static stability characterized by a vertical increasing gradient at $850 \mathrm{hPa}$ ? How does the change in static stability influence the maintenance of the MH?

Since the thermodynamic structure of the atmosphere can be modified by the forcing of external diabatic heating, the vertical distribution of static stability and its association with diabatic heating are explored in Fig. 10. Static stability enhances with altitude over the key region and reaches its maximum at around $800 \mathrm{hPa}$, where the strongest diabatic cooling due mainly to longwave radiative cooling appears. As diabatic cooling stabilizes the air, the atmosphere there becomes the most stable, showing a much larger positive vertical gradient of static stability over the South Indian Ocean than over the southern Africa. Hence, as a response to the forcing of external heating, the static stability increases with height over the subtropical South Indian Ocean in the lower troposphere.

Another important question is how the change in static stability influences the maintenance of the structure of the $\mathrm{MH}$ over the ocean. Considering the short-term evolution, the downward transport of air with larger static stability could stabilize the low-level atmosphere and then weaken the anticyclonic vorticity source forced by the 
vertical gradient of diabatic heating, referred to in Equation 4. In other words, the increasing stability of the atmosphere is unfavorable for the further development of the disturbance vortex source, which partly counteracts the effect of the vertical gradient of diabatic heating. From a long-term evolution perspective, the geostrophic vorticity advection $(\beta v)$ from low latitudes by the northerlies should be excited to balance the negative vorticity source forced by the stabilization of the low-level atmosphere. Hence, over the subtropical Indian Ocean, the vertical increasing diabatic cooling tends to stimulate southerly wind, which is partly compensated by northerly wind motivated by the change in static stability. That is, the southerly geostrophic vorticity advection on the east side of the $\mathrm{MH}$ is a result of the counterbalance between the vertical gradient of diabatic heating and the change in static stability.

\section{Conclusions and discussion}

This study has investigated the dynamic and thermal structures of the climatological $\mathrm{MH}$ and its maintenance mechanisms in austral winter based on monthly reanalysis data from JRA-55. The MH has a cell-type anticyclonic structure and spans from the southern Africa to the subtropical South Indian Ocean in the lower troposphere below $700 \mathrm{hPa}$. Its activity center tilts equatorward and westward with height due to its thermal structure, which shows a warmer distribution over the north and west of the $\mathrm{MH}$. The dynamic structure of the $\mathrm{MH}$ is characterized by large-scale subsidence and shows a west-to-east discrepancy: a stronger descending motion to the east is the sinking branch of the single-loop Hadley circulation triggered by South Asian monsoonal convective heating; a weaker descending motion to the west results from 
the southern branch of the double-loop Hadley circulation associated with much weaker

African monsoonal convective heating.

By applying the complete form of the vertical vorticity tendency equation, the maintenance mechanism of the anticyclonic structure of the $\mathrm{MH}$ is simplified as the causes of the spatial distribution of advection of geostrophic vorticity $(\beta v)$. It is a joint result of the vertical gradient of diabatic heating, frictional dissipation, and the change in static stability. It shows a west-to-east discrepancy over the southern Africa and the subtropical South Indian Ocean. The northerlies over the southern Africa can be regarded as the balance of the strong friction effect and the relatively weaker vertical gradient of diabatic heating, whereas the southerlies over the subtropical South Indian Ocean are maintained by the effect of the stronger vertical gradient of diabatic heating and the change in static stability. A schematic diagram is presented in Fig. 11. Diabatic heating within the $\mathrm{MH}$, as a combination of sensible heating and longwave radiative cooling, shows a vertical decreasing gradient in the lower troposphere. According to the Sverdrup balance (Liu et al. 2004), diabatic heating with a vertical decreasing gradient tends to generate southerlies with stronger magnitude over the subtropical South Indian Ocean than over the southern Africa. Over the southern Africa, strong topographic friction dissipation balances the effect of the vertical gradient of diabatic heating, and northerlies prevail. Over the South Indian Ocean, the strongest diabatic cooling dominated by longwave radiative cooling appears at $800 \mathrm{hPa}$ and makes the atmosphere there the most stable. By the strong descending motion of the Hadley circulation triggered by the South Asian monsoonal convection, air with higher static 
stability is transported downward to lower layers. It can stabilize the low-level atmosphere and partly counteract the effect of the vertical gradient of diabatic heating.

Whereas the effect of vertical gradient of diabatic heating is a bit stronger than the change in static stability over the South Indian Ocean, and thus southerlies prevail there. The dynamic and thermal processes relevant to the maintenance of the $\mathrm{MH}$ reveal an important aspect of the winter climate over the southern Africa and the subtropical South Indian Ocean.

This study has emphasized the role of longwave radiative cooling in dominating the vertical distribution of diabatic heating. It is still unclear why the strongest longwave radiative cooling appears over the South Indian Ocean at around $800 \mathrm{hPa}$. In austral winter, longwave radiative cooling characterizes the entire subtropical South Indian Ocean, whereas it is constrained over the eastern South Indian Ocean in summer (Wu and Liu 2003; Liu et al. 2004; Miyasaka and Nakamura 2010). A similar seasonal discrepancy can be found in the spatial displacement of the MH (Miyamoto et al. 2018), where a feedback might occur. As suggested by previous studies, a positive feedback between marine boundary layer clouds, longwave radiative cooling, and subtropical highs appears over the eastern portion of the ocean basin, maintaining the summertime subtropical highs (Klein and Hartmann 1993; Wu et al 2009; Norris and Klein 2000; Miyasaka and Nakamura 2005). Marine boundary layer clouds over the eastern portion of the ocean basin can induce strong longwave radiative cooling aloft (Norris 1998; Wu et al. 2009; Wei et al. 2017), which plays an important role in maintaining the subtropical highs (Miyasaka and Nakamura 2005; Liu et al. 2004). In return, the 
equatorward flow along the eastern flank of the subtropical highs can generate cold air

551 advection from high latitudes and coastal upwelling along the east coast of the ocean.

552 This cools the local sea surface temperature and increases the static stability, which

553 favors the growth of marine boundary layer clouds (Klein and Hartmann 1993; Norris

554 and Klein 2000; Wei et al 2017). For the South Indian Ocean, Miyamoto et al. (2018)

555 have shown that in contrast to the summertime when low clouds are maximized off the

556 west coast of Australia, the low clouds in wintertime are distributed more zonally across

557 the basin. This is consistent with the seasonal variability in the displacement of

558 longwave radiative cooling. It implies that strong longwave radiative cooling over the

559 subtropical South Indian Ocean might be related to the radiative effect of low-level

560 clouds. However, the feedback between low clouds, longwave radiative cooling, and

561 the MH in winter is still unclear. Furthermore, the displacement of low clouds and the

562 center of the MH seems unique among other ocean basins where the strongest signals

563 appear in the eastern portion. All these problems deserve further investigation to

564 disclose the nature and origin of the $\mathrm{MH}$.

\section{Appendix}

Referring to the previous studies (Liu et al. 2001; Wu et al. 1999; Liu et al. 1999a;

b), the complete form of the vertical tendency equation can be deduced as follows.

The Ertel potential vorticity can be written as:

$$
P_{E}=\alpha \overrightarrow{\zeta_{a}} \cdot \nabla \theta
$$

570 where $\overrightarrow{\zeta_{a}}$ denotes the three dimensional absolute vorticity, $\theta$ is potential temperature,

571 and $\alpha$ is specific volume, $\nabla=\frac{\partial}{\partial x} \vec{\imath}+\frac{\partial}{\partial y} \vec{\jmath}+\frac{\partial}{\partial z} \vec{k}$. Equation A1 can also be rewritten as: 


$$
\alpha(f+\zeta)=\frac{P_{E}}{\theta_{z}}-\alpha \nabla \times \vec{V} \cdot \frac{\nabla_{h} \theta}{\theta_{z}}
$$

$573 \theta_{z}=\frac{\partial \theta}{\partial z}$ is static stability, $\vec{V}$ denotes the three dimensional velocity vector, $\nabla_{h}=$

$574 \frac{\partial}{\partial x} \vec{\imath}+\frac{\partial}{\partial y} \vec{\jmath}$. The thermodynamic parameter $C_{D}=\alpha \nabla \times \vec{V} \cdot \frac{\nabla_{h} \theta}{\theta_{z}}$ represents the mapping

575 of horizontal vorticity to vertical vorticity per unit mass. Thus, Equation A2 can be 576 written as:

$$
\alpha(f+\zeta)=\frac{P_{E}}{\theta_{z}}-C_{D}
$$

578 Let $\mathrm{dA} / \mathrm{dt}$ be the total derivative of $\mathrm{A}$ in the inertial frame $\left(\frac{d A}{d t}=\frac{\partial A}{\partial t}+\vec{V} \cdot \nabla A\right)$, Equation A3 can be written as:

$$
\frac{d[\alpha(f+\zeta)]}{d t}=\frac{d}{d t}\left(\frac{P_{E}}{\theta_{z}}-C_{D}\right)
$$

581

582

And Equation A4 also can be:

$$
(f+\zeta) \frac{d \alpha}{d t}+\alpha \frac{d(f+\zeta)}{d t}=\frac{d}{d t}\left(\frac{P_{E}}{\theta_{z}}-C_{D}\right)
$$

From the equation of state for an ideal gas $(P \alpha=R T)$, A5 can be written as:

$$
\frac{\partial \zeta}{\partial t}+\vec{V} \cdot \nabla \zeta+\beta v=(1-K)(f+\zeta) \frac{\omega}{P}-(f+\zeta) \frac{1}{\theta} \frac{d \theta}{d t}+\frac{1}{\alpha} \frac{d}{d t}\left(\frac{P_{E}}{\theta_{z}}-C_{D}\right)
$$

$P$ represents the air pressure. $K=R / C p, R$ and $C p$ are the gas constant and specific heat capacity in dry air at constant pressure. $\beta=\frac{\partial f}{\partial y}$. Considering the definition of Ertel potential vorticity (A1), the Equation A7 decribing the variation of potential vorticity can be gained.

$$
\frac{d P_{E}}{d t}=\alpha \overrightarrow{F_{\zeta}} \cdot \nabla \theta+\alpha \overrightarrow{\zeta_{a}} \cdot \nabla Q
$$

As a result, Equation A6 can be rewritten as:

$$
\begin{gathered}
\frac{\partial \zeta}{\partial t}+\vec{V} \cdot \nabla \zeta+\beta v=(1-K)(f+\zeta) \frac{\omega}{P}-(f+\zeta) \frac{1}{\theta} \frac{d \theta}{d t}+\frac{1}{\theta_{z}} \overrightarrow{F_{\zeta}} \cdot \nabla \theta+\frac{f+\zeta}{\theta_{z}} \frac{\partial Q}{\partial z}- \\
\frac{1}{\theta_{z}} \frac{\partial v}{\partial z} \frac{\partial Q}{\partial x}+\frac{1}{\theta_{z}} \frac{\partial u}{\partial z} \frac{\partial Q}{\partial y}+\frac{1}{\alpha} P_{E} \frac{d}{d t}\left(\frac{1}{\theta_{z}}\right)-\frac{1}{\alpha} \frac{d}{d t}\left(C_{D}\right)
\end{gathered}
$$

where $\overrightarrow{F_{\zeta}}$ denotes the friction dissipation, calculated as the residual from the three 
dimensional vorticity equation (Holton and Hakim, 2012), $Q$ is diabatic heating rate. This is the complete form of the vertical vorticity tendency equation (A8), in which, the relative contributions of dynamical and themodynamical processes to the tendency of vertical vorticity can be evaluated.

\section{Acknowledgement}

This work is jointly supported by the National Key Research and Development Programs of China (Project No. 2016YFA0600601 and 2019YFC1510400), National Natural Science Foundation of China (Project No. 41775043), and Guangdong Province Key Laboratory for Climate Change and Natural Disaster Studies (Grant 2020B1212060025).

\section{Declarations}

\section{Funding}

This work received funding from the National Key Research and Development Programs of China (Project No. 2016YFA0600601 and 2019YFC1510400), National Natural Science Foundation of China (Project No. 41775043), and Guangdong Province Key Laboratory for Climate Change and Natural Disaster Studies (Grant 2020B1212060025).

\section{Conflicts of interest}

The authors declare that they have no competing interests.

\section{Availability of data and material}

JRA-55 reanalysis data are available from http://jra.kishou.go.jp/JRA- 
615 55/index_en.html. NCEP-2 reanalysis data can be downloaded from 616 http://psl.noaa.gov/data/gridded/data.ncep.reanalysis2.html. ERA-Interim reanalysis 617 data come from https://www.ecmwf.int/en/forecasts/datasets/reanalysis-datasets/era618 interim.

\section{Code availability}

620 The data analysis was carried out using NCAR Command Language (NCL).

\section{Authors' contributions}

$622 \quad$ Not applicable.

623 Ethics approval

$624 \quad$ Not applicable.

625 Consent to participate

$626 \quad$ Not applicable.

627 Consent for publication

$628 \quad$ Not applicable.

629 
630

631

632

633

634

635

636

637

638

639

640

641

642

643

644

645

646

647

648

649

650

651

\section{References}

Behera SK, Yamagata T (2001) Subtropical SST dipole events in the southern Indian Ocean. Res Lett 28:327-330. http://doi.org/10.1029/2000GL011451

Chen G, Iwasaki T, Qin H, Sha W (2014) Evaluation of the warm-season diurnal variability over East Asia in recent reanalyses JRA-55, ERA-Interim, NCEP CFSR, and NASA MERRA. J Clim 27:5517-5537. https://doi.org/10.1175/JCLI-D-1400005.1

Chen P, Hoerling MP, Dole RM (2001) The origin of subtropical anticyclones. J Atmos Sci 58:1827-1835. https://doi.org/10.1175/15200469(2001)058<1827:TOOTSA $>2.0 . \mathrm{CO} ; 2$

Cook KH (2000) The South Indian convergence zone and interannual rainfall variability over Southern Africa. J Clim 13:3789-3804. https://doi.org/10.1175/1520-0442(2000)013<3789:TSICZA>2.0.CO;2

Han X, Wei F, Chen X (2017) Influence of the Anomalous Patterns of the Mascarene and Australian Highs on Precipitation during the Prerainy Season in South China. Adv Meteorol . https://doi.org/10.1155/2017/6408029

Harada Y, Kamahori H, Kobayashi C, et al (2016) The JRA-55 reanalysis: Representation of atmospheric circulation and climate variability. J Meteorol Soc Japan 94:269-302. https://doi.org/10.2151/jmsj.2016-015

Harrison MSJ (1984) A generalized classification of South African summer rainbearing synoptic systems. J Climatol 4:547-560. https://doi.org/10.1002/joc.3370040510 
652

653

654

655

656

657

658

659

660

661

662

663

664

665

666

667

668

669

670

671

672

673

Holton JR, Hakim GJ (2012) An introduction to dynamic meteorology: Fifth edition. pp 100-102. https://doi.org/10.1016/C2009-0-63394-8

Hoskins BJ, Rodwell MJ (1995) A model of the Asian summer monsoon. Part I: the global scale. J Atmos Sci 52:1329-1340. https://doi.org/10.1175/15200469(1995)052<1329:AMOTAS>2.0.CO;2

Hoskins BJ (1996) On the existence and strength of the summer subtropical anticyclones. Bull Am Meteorol Soc 77:1287-1292.

Klein SA, Hartmann DL (1993) The seasonal cycle of low stratiform clouds. J Clim $6: 1587-1606$.

https://doi.org/10.1175/15200442(1993)006<1587:TSCOLS $>2.0 . \mathrm{CO} ; 2$

Kobayashi S, Ota Y, Harada Y, et al (2015) The JRA-55 reanalysis: General specifications and basic characteristics. J Meteorol Soc Japan 93:5-48. https://doi.org/10.2151/jmsj.2015-001

Krishnamurti TN, Bhalme HN (1976) Oscillations of a monsoon system. Part I. Observational aspects. J Atmos Sci 33:1937-1954. https://doi.org/10.1175/15200469(1976)033<1937:OOAMSP>2.0.CO;2

Lee SK, Mechoso CR, Wang C, Neelin JD (2013) Interhemispheric influence of the northern summer monsoons on southern subtropical anticyclones. J Clim 26:10193-10204. https://doi.org/10.1175/JCLI-D-13-00106.1

Li X, Wen Z, Chen D, Chen Z (2019) Decadal transition of the leading mode of interannual moisture circulation over east Asia-western North Pacific: Bonding to different evolution of ENSO. J Clim 32:289-308. https://doi.org/10.1175/JCLI-D- 
18-0356.1

Li X, Wen Z, Huang WR (2020) Modulation of South Asian Jet wave train on the extreme winter precipitation over Southeast China: Comparison between 2015/16 and 2018/19. J Clim 33:4065-4081. https://doi.org/10.1175/JCLI-D-19-0678.1

Liu Y, Wu G, Ren R (2004) Relationship between the subtropical anticyclone and diabatic heating. J Clim 17:682-698. https://doi.org/10.1175/15200442(2004)017<0682:RBTSAA >2.0.CO;2

Liu Y, Wu G, Liu H, Liu P (2001) Condensation heating of the Asian summer monsoon and the subtropical anticyclone in the eastern Hemisphere. Clim Dyn 17:327-338. https://doi.org/10.1007/s003820000117

Liu Y, Liu H, Liu P, Wu G (1999a) The effect of spatially nonuniform heating on the formation and variation of subtropical high. Part II: Land surface sensible heating and east Pacific subtropical high. Acta Meteorol Sin 57:385-396 (in Chinese)

Liu Y, Wu G, Liu H, Liu P (1999b) The effect of spatially nonuniform heating on the formation and variation of subtropical high. Part III: Condensation heating and South Asian high and western Pacific subtropical high. Acta Meteorol Sin 57:525538 (in Chinese)

Luo H, Yanai M (1984) The large-scale circulation and heat sources over the Tibetan Plateau and surrounding areas during the early summer of 1979. Part II: Heat and moisture budgets. Mon Weather Rev 112:966-989. https://doi.org/10.1175/15200493(1984)112<0966:tlscah $>2.0 . c 0 ; 2$

Manatsa D, Morioka Y, Behera SK, et al (2014) Impact of Mascarene High variability 
696

on the East African "short rains." Clim Dyn 42:1259-1274. https://doi.org/10.1007/s00382-013-1848-z

Miyamoto A, Nakamura H, Miyasaka T (2018) Influence of the subtropical high and storm track on low-cloud fraction and its seasonality over the South Indian Ocean. J Clim 31:4017-4039. https://doi.org/10.1175/JCLI-D-17-0229.1

Miyasaka T, Nakamura H (2010) Structure and mechanisms of the Southern Hemisphere summertime subtropical anticyclones. J Clim 23:2115-2130. https://doi.org/10.1175/2009JCLI3008.1

Miyasaka T, Nakamura H (2005) Structure and formation mechanisms of the Northern Hemisphere summertime subtropical highs. J Clim 18:5046-5065. https://doi.org/10.1175/JCLI3599.1

Morioka Y, Tozuka T, Masson S, et al (2012) Subtropical dipole modes simulated in a coupled general circulation model. J Clim 25:4029-4047. https://doi.org/10.1175/JCLI-D-11-00396.1

Morioka Y, Tozuka T, Yamagata T (2010) Climate variability in the southern Indian Ocean as revealed by self-organizing maps. Clim Dyn 35:1075-1088. https://doi.org/10.1007/s00382-010-0843-x

Norris JR (1998) Low cloud type over the ocean from surface observations. Part II: Geographical and seasonal variations. J Clim 11:383-403. https://doi.org/10.1175/1520-0442(1998)011<0383:LCTOTO>2.0.CO;2

Norris JR, Klein SA (2000) Low cloud type over the ocean from surface observations. Part III: Relationship to vertical motion and the regional surface synoptic 
environment. J Clim 13:245-256. https://doi.org/10.1175/15200442(2000)013<0245:LCTOTO $>2.0 . \mathrm{CO} ; 2$

Rodwell MJ, Hoskins BJ (2001) Subtropical anticyclones and summer monsoons. J Clim 14:3192-3211. https://doi.org/10.1175/15200442(2001)014<3192:SAASM>2.0.CO;2

Rodwell MJ, Hoskins BJ (1996) Monsoons and the dynamics of deserts. Q J R Meteorol Soc 122:1385-1404. https://doi.org/10.1256/smsqj.53407

Ting M (1994) Maintenance of Northern Summer Stationary Waves in a GCM. J. Atmos. Sci. $\quad 51: 3286-3308 . \quad$ https://doi.org/10.1175/15200469(1994)051<3286:monssw>2.0.co;2

Vidya PJ, Ravichandran M, Subeesh MP, et al (2020) Global warming hiatus contributed weakening of the Mascarene High in the Southern Indian Ocean. Scientific Reports, 10:3255. https://doi.org/10.1038/s41598-020-62006-x

Wei W, Li W, Deng Y, et al (2018) Dynamical and thermodynamical coupling between the North Atlantic subtropical high and the marine boundary layer clouds in boreal summer. Clim Dyn 50:2457-2469. https://doi.org/10.1007/s00382-017-3750-6

Wu GX, Liu Y (2003) Summertime quadruplet heating pattern in the subtropics and the associated atmospheric circulation. Geophys Res Lett 30:3-6. https://doi.org/10.1029/2002g1016209

Wu GX, Liu Y, Zhu X, et al (2009) Multi-scale forcing and the formation of subtropical desert and monsoon. Ann Geophys 27:3631-3644. https://doi.org/10.5194/angeo27-3631-2009 
Wu GX, Liu Y, Liu P (1999) The effect of spatially nonuniform heating on the formation and variation of subtropical high. I. Scale analysis. Acta Meteorol Sin 57:257-263 (in Chinese)

Wu GX, Liu H (1999) Complete form of vertical vorticity tendency equation and slantwise vorticity development. Acta Meteorol Sin 57:1-13(in Chinese)

Wu GX (2001) Comparison between the complete-form vorticity and the traditional vorticity equation. Acta Meteorol Sin 59(4):285-392(in Chinese)

Xue F, Wang H, He J (2004) Interannual variability of Mascarene high and Australian high and their influences on East Asian summer monsoon. J Meteorol Soc Japan 82:1173-1186. https://doi.org/10.2151/jmsj.2004.1173

Yanai M, Esbensen S, Chu J-H (1973) Determination of bulk properties of tropical cloud clusters from large-scale heat and moisture budgets. J Atmos Sci 30:611627. https://doi.org/10.1175/1520-0469(1973)030<0611:DOBPOT>2.0.CO;2 


\section{Figure captions}

Fig. 1 Distributions of the climatological mean (1979-2017) of geopotential height (shading; units: gpm) and horizontal wind (vectors; units: $\mathrm{m} \mathrm{s}^{-1}$ ) at (a) $500 \mathrm{hPa}$, (b) $700 \mathrm{hPa}$, (c) $850 \mathrm{hPa}$, and (d) $1000 \mathrm{hPa}$ in austral winter (JJA).

Fig. 2 (a) Meridional-vertical section of temperature (shading; units: K) and the meridional deviation of geopotential height calculated as the difference between other latitudes and the equator (contours; units: gpm) averaged over $20^{\circ} \mathrm{E}-110^{\circ} \mathrm{E}$. (b) Zonal-vertical section of zonal deviation of temperature (shading; units: K) and standardized zonal deviation of geopotential height (contours; units: gpm) averaged over $35^{\circ} \mathrm{S}-20^{\circ} \mathrm{S}$.

Fig. 3 (a) Vertical velocity at $500 \mathrm{hPa}$ (shading; units: $\mathrm{Pa} \mathrm{s}^{-1}$ ), horizontal wind (vectors; units: $\mathrm{m} \mathrm{s}^{-1}$ ), and geopotential height at $850 \mathrm{hPa}$ (contours; interval: $10 \mathrm{gpm}$ ). Distribution of meridional-vertical section of circulation (vectors; meridional wind: $\mathrm{m} \mathrm{s}^{-1}$; vertical velocity: $-10^{-2} \mathrm{~Pa} \mathrm{~s}^{-1}$ ) and vertical velocity (shading; units: $\mathrm{Pa} \mathrm{s}^{-1}$ ) averaged over (b) $20^{\circ} \mathrm{E}-50^{\circ} \mathrm{E}$ and (c) $60^{\circ} \mathrm{E}-110^{\circ} \mathrm{E}$.

Fig. 4 Combination of the distributions of the (a) relative vorticity advection, (b) geostrophic vorticity advection, (c) effect of vertical velocity, (d) effect of heating itself, (e) frictional dissipation effect, the (f) vertical, (g) zonal, and (h) meridional gradient of diabatic heating, (i) change in static stability, and (j) mapping from horizontal vorticity to vertical vorticity at $850 \mathrm{hPa}$ (shading; units: $10^{-10} \mathrm{~s}^{-2}$ ). Dashed rectangles denote the regions over the southern Africa $\left(35^{\circ} \mathrm{S}-15^{\circ} \mathrm{S}, 15^{\circ} \mathrm{E}-\right.$ $\left.35^{\circ} \mathrm{E}\right)$ and the South Indian Ocean $\left(35^{\circ} \mathrm{S}-15^{\circ} \mathrm{S}, 60^{\circ} \mathrm{E}-110^{\circ} \mathrm{E}\right)$. 
Fig. 5 Regional average of geostrophic vorticity advection (V2), frictional dissipation effect (V5), vertical gradient of diabatic heating (V6), and change in static stability (V9) over the southern Africa (continental region, $35^{\circ} \mathrm{S}-15^{\circ} \mathrm{S}, 15^{\circ} \mathrm{E}-$ $35^{\circ} \mathrm{E}$; olive bars) and over the South Indian Ocean (ocean region, $35^{\circ} \mathrm{S}-15^{\circ} \mathrm{S}$, $60^{\circ} \mathrm{E}-110^{\circ} \mathrm{E}$; orange bars). The boundaries of the two regions are overlaid in Fig. 4. The units of the four terms are $10^{-10} \mathrm{~s}^{-2}$.

Fig. 6 Zonal-vertical section of distributions of (a) total heating rate, (b) latent heating rate, (c) sensible heating rate, and (d) longwave radiative heating rate averaged over $35^{\circ} \mathrm{S}-15^{\circ} \mathrm{S}$ (shading; units: $\mathrm{K}_{\text {day }}{ }^{-1}$ ).

Fig. 7 Vertical profiles of TH (black line), SH (brown line), LH (blue line), and LW (purple line) averaged over (a) the southern Africa (the average terrain is masked) and (b) South Indian Ocean (units: $\mathrm{K}_{\mathrm{day}}{ }^{-1}$ ).

Fig. 8 Spatial distributions of (a) change in static stability, (b) vertical advection change in static stability, and (c) horizontal advection change in static stability (units: $10^{-}$ $\left.{ }^{10} \mathrm{~s}^{-2}\right)$

Fig. 9 (a) Spatial distributions of vertical velocity (units: $\mathrm{m} \mathrm{s}^{-1}$ ), and (b) vertical gradient of static stability at $850 \mathrm{hPa}$ (units: $10^{-6} \mathrm{~K} \mathrm{~m}^{-2}$ ).

Fig. 10 Zonal-vertical section of distributions of total heating rate (shading; units: $\mathrm{K}$ day $^{-1}$ ) and static stability (contours; interval: $10^{-3} \mathrm{~K} \mathrm{~m}^{-1}$ ) averaged over $30^{\circ} \mathrm{S}-$ $20^{\circ} \mathrm{S}$

Fig. 11 Schematic diagram showing the maintenance mechanisms of the anticyclonic structure of the MH. The solid blue denotes the vertical profile of diabatic heating 
over the key region. Dashed arrows in red, blue, and orange represent the effect

799 of frictional dissipation, the vertical gradient of diabatic heating, and the change

800 in static stability on the maintenance of meridional winds. The regions marked

801 with the red line and the blue shading over the subtropical South Indian Ocean

802 indicate the center of static stability and diabatic cooling, respectively. The

803 downward orange arrow denotes descending motion associated with the

804 monsoonal Hadley cell, which can transport higher static stability downward.

805 

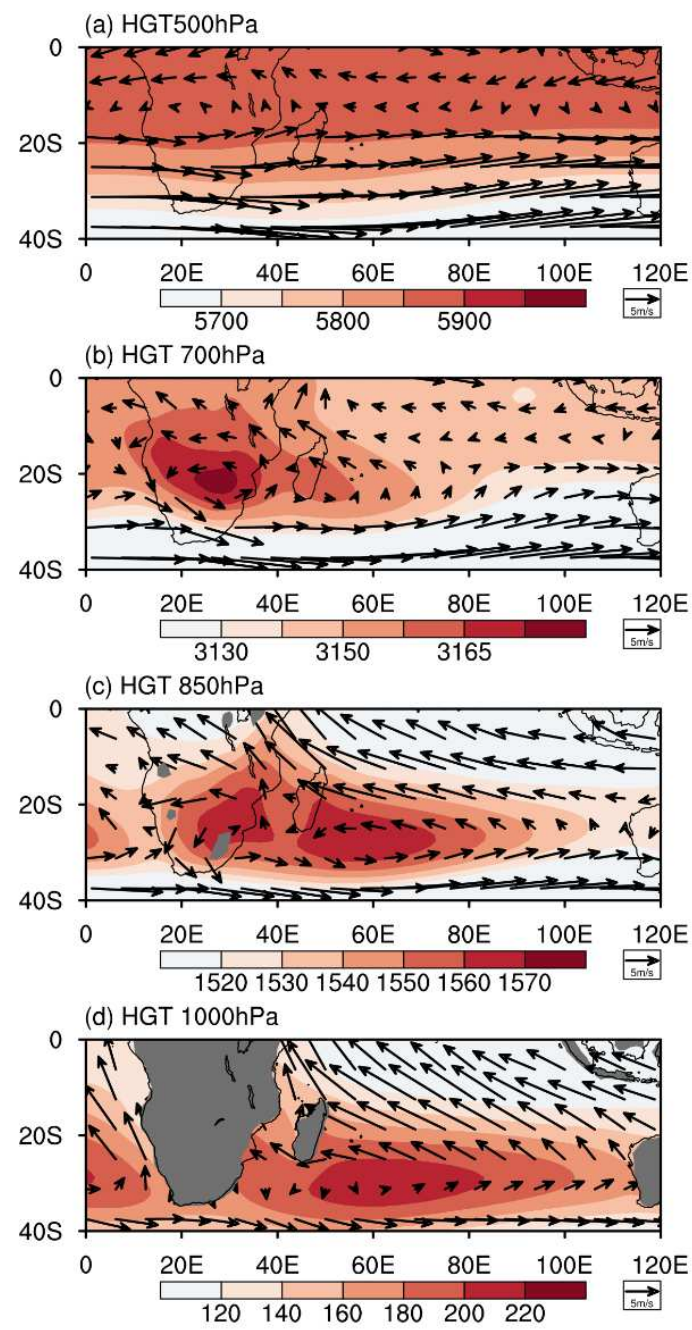

807 Fig. 1 Distributions of the climatological mean (1979-2017) of geopotential height 808 (shading; units: gpm) and horizontal wind (vectors; units: $\mathrm{m} \mathrm{s}^{-1}$ ) at (a) $500 \mathrm{hPa}$, $809 \quad$ (b) $700 \mathrm{hPa}$, (c) $850 \mathrm{hPa}$, and (d) $1000 \mathrm{hPa}$ in austral winter (JJA). 
(a) HGT \& T

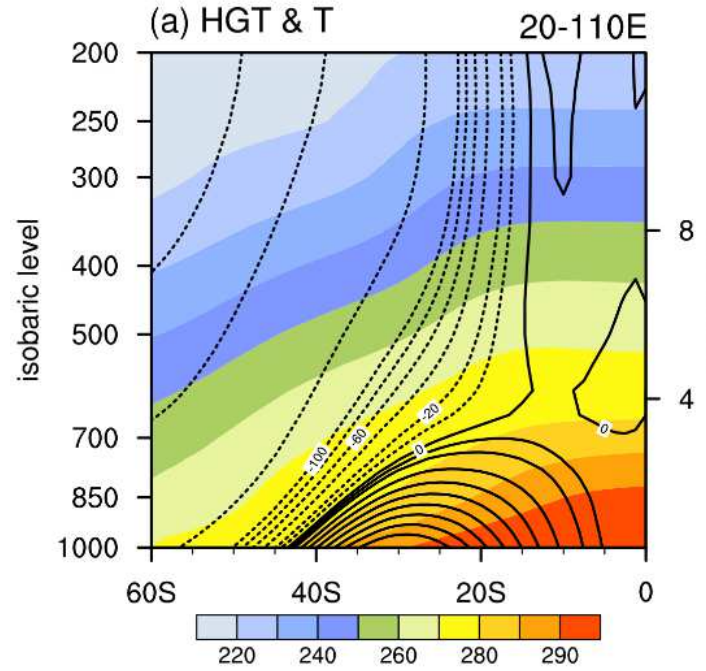

(b) HGT \& T

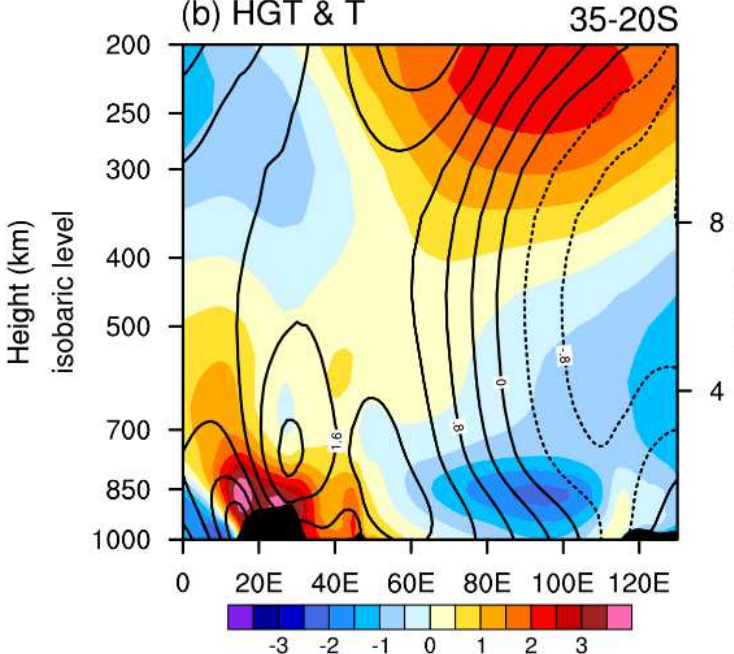

Fig. 2 (a) Meridional-vertical section of temperature (shading; units: K) and the meridional deviation of geopotential height calculated as the difference between other latitudes and the equator (contours; units: gpm) averaged over $20^{\circ} \mathrm{E}-110^{\circ} \mathrm{E}$. (b) Zonal-vertical section of zonal deviation of temperature (shading; units: K) and standardized zonal deviation of geopotential height (contours; units: gpm) averaged over $35^{\circ} \mathrm{S}-20^{\circ} \mathrm{S}$. 
(a) HGT,UV(850) \& Omega(500)
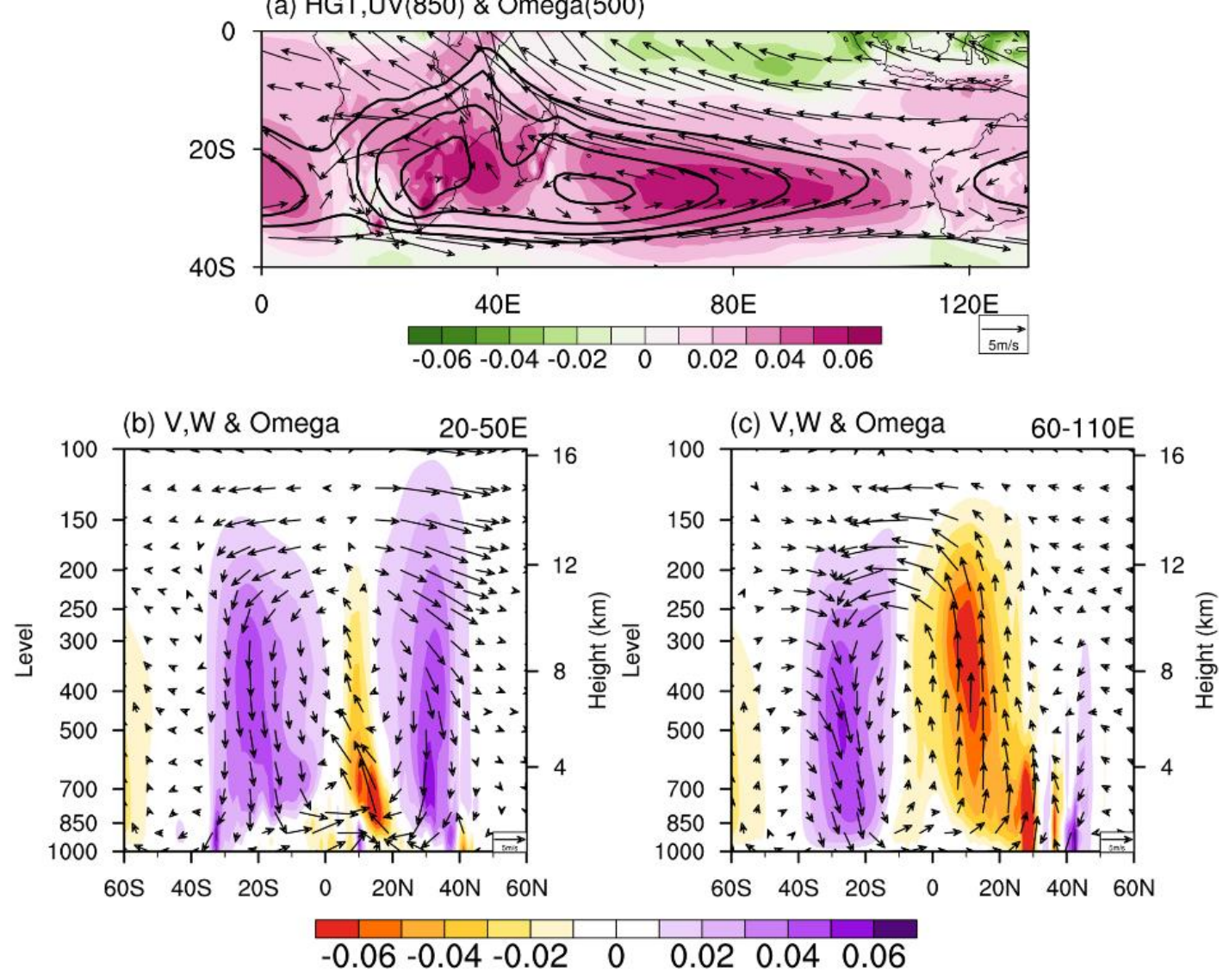

818 Fig. 3 (a) Vertical velocity at $500 \mathrm{hPa}$ (shading; units: $\mathrm{Pa} \mathrm{s}^{-1}$ ), horizontal wind (vectors; units: $\mathrm{m} \mathrm{s}^{-1}$ ), and geopotential height at $850 \mathrm{hPa}$ (contours; interval: $10 \mathrm{gpm}$ ). Distribution of meridional-vertical section of circulation (vectors; meridional wind: $\mathrm{m} \mathrm{s}^{-1}$; vertical velocity: $-10^{-2} \mathrm{~Pa} \mathrm{~s}^{-1}$ ) and vertical velocity (shading; units: $\mathrm{Pa} \mathrm{s}^{-1}$ ) averaged over (b) $20^{\circ} \mathrm{E}-50^{\circ} \mathrm{E}$ and (c) $60^{\circ} \mathrm{E}-110^{\circ} \mathrm{E}$. 


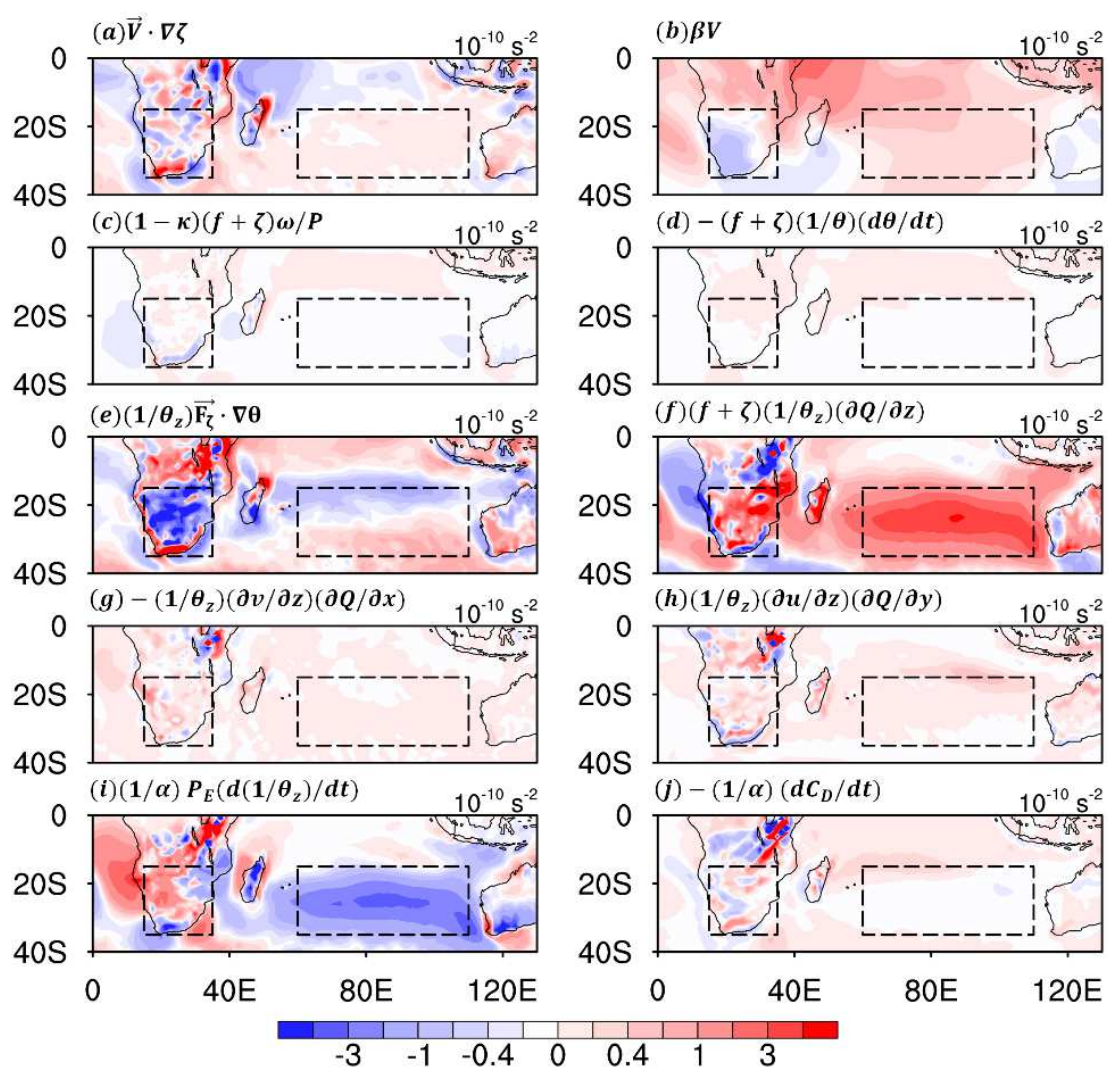

824 Fig. 4 Combination of the distributions of the (a) relative vorticity advection, (b) geostrophic vorticity advection, (c) effect of vertical velocity, (d) effect of heating itself, (e) frictional dissipation effect, the (f) vertical, (g) zonal, and (h) meridional gradient of diabatic heating, (i) change in static stability, and (j) mapping from horizontal vorticity to vertical vorticity at $850 \mathrm{hPa}$ (shading; units: $10^{-10} \mathrm{~s}^{-2}$ ). Dashed rectangles denote the regions over the southern Africa $\left(35^{\circ} \mathrm{S}-15^{\circ} \mathrm{S}, 15^{\circ} \mathrm{E}-\right.$ $\left.35^{\circ} \mathrm{E}\right)$ and the South Indian Ocean $\left(35^{\circ} \mathrm{S}-15^{\circ} \mathrm{S}, 60^{\circ} \mathrm{E}-110^{\circ} \mathrm{E}\right)$. 


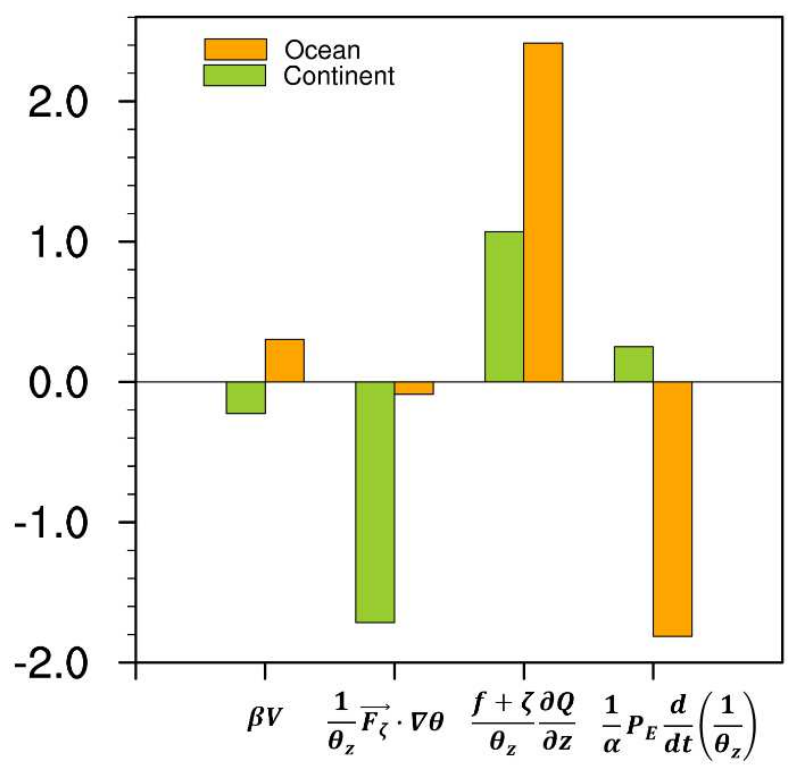

832 Fig. 5 Regional average of geostrophic vorticity advection (V2), frictional dissipation effect (V5), vertical gradient of diabatic heating (V6), and change in static stability (V9) over the southern Africa (continental region, $35^{\circ} \mathrm{S}-15^{\circ} \mathrm{S}, 15^{\circ} \mathrm{E}-$ $35^{\circ} \mathrm{E}$; olive bars) and over the South Indian Ocean (ocean region, $35^{\circ} \mathrm{S}-15^{\circ} \mathrm{S}$, $60^{\circ} \mathrm{E}-110^{\circ} \mathrm{E}$; orange bars). The boundaries of the two regions are overlaid in Fig. 4. The units of the four terms are $10^{-10} \mathrm{~s}^{-2}$. 

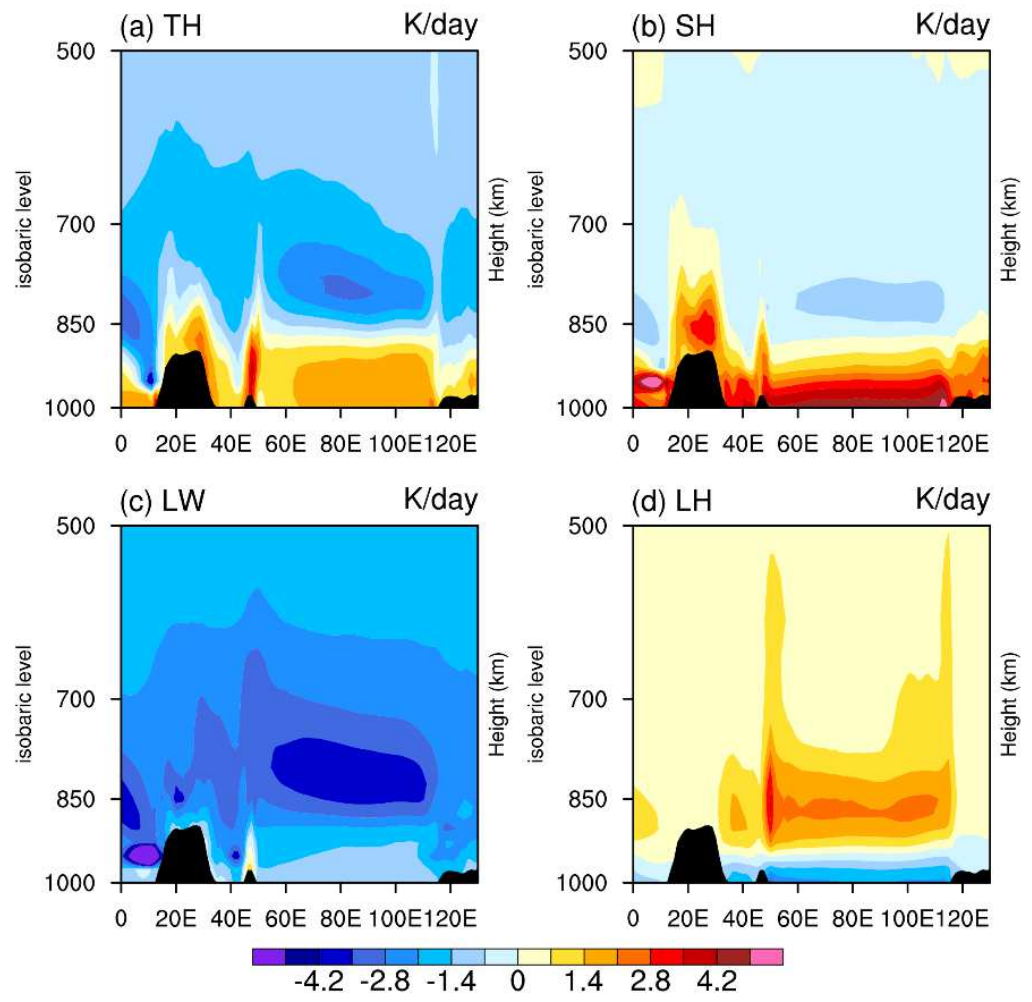

839 Fig. 6 Zonal-vertical section of distributions of (a) total heating rate, (b) latent heating rate, (c) sensible heating rate, and (d) longwave radiative heating rate averaged over $35^{\circ} \mathrm{S}-15^{\circ} \mathrm{S}$ (shading; units: $\mathrm{K}$ day $^{-1}$ ). 


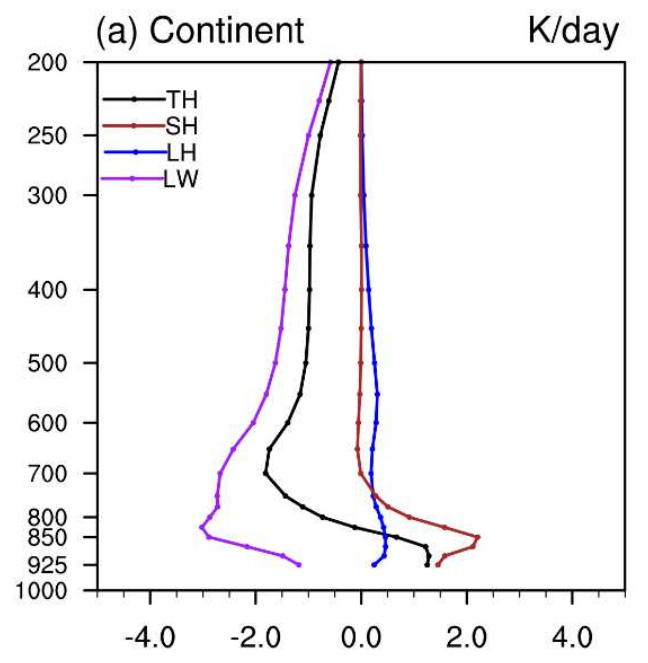

(b) Ocean

K/day

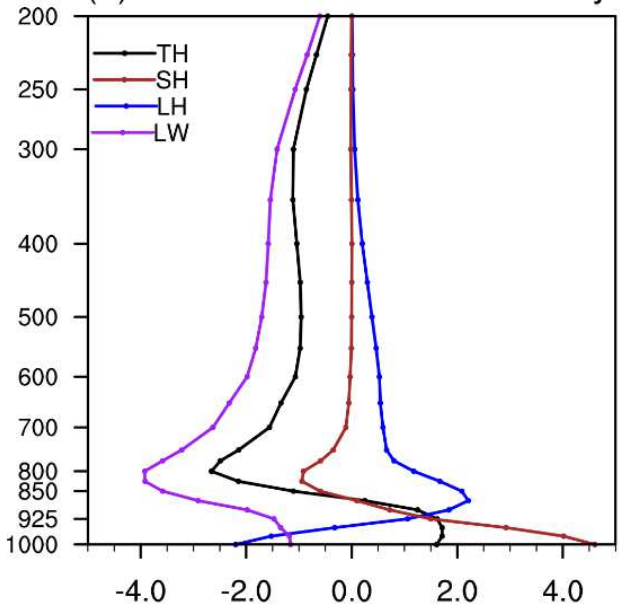

Fig. 7 Vertical profiles of TH (black line), SH (brown line), LH (blue line), and LW (purple line) averaged over (a) the southern Africa (the average terrain is masked) and (b) South Indian Ocean (units: $\mathrm{K} \mathrm{day}^{-1}$ ). 

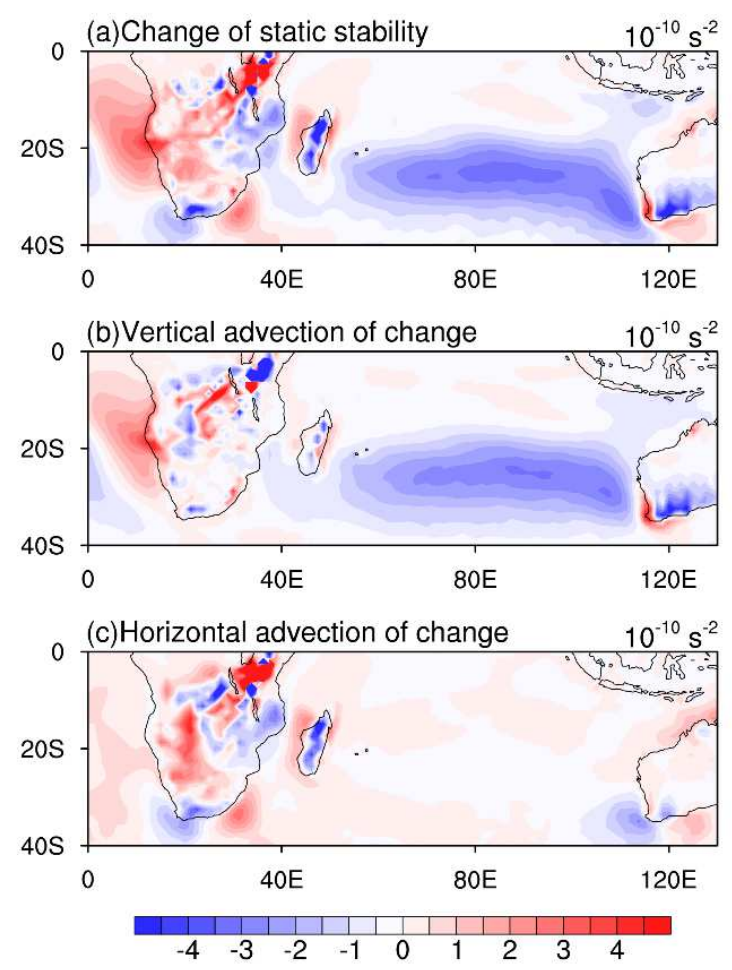

847 Fig. 8 Spatial distributions of (a) change in static stability, (b) vertical advection change in static stability, and (c) horizontal advection change in static stability (units: $10^{-}$ $\left.{ }^{10} \mathrm{~s}^{-2}\right)$. 

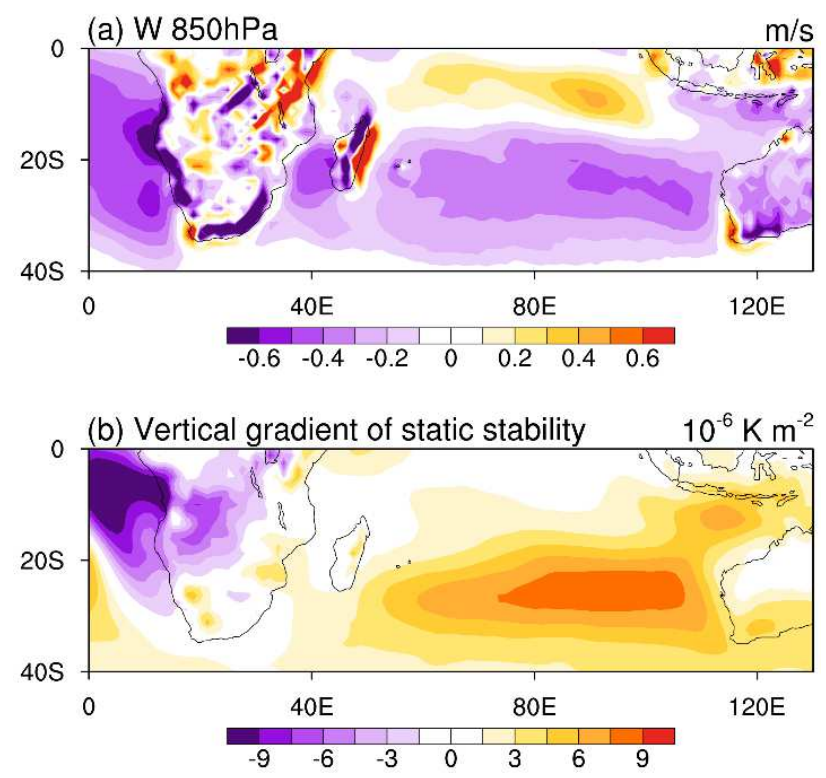

851 Fig. 9 (a) Spatial distributions of vertical velocity (units: $\mathrm{m} \mathrm{s}^{-1}$ ), and (b) vertical gradient of static stability at $850 \mathrm{hPa}$ (units: $10^{-6} \mathrm{~K} \mathrm{~m}^{-2}$ ). 


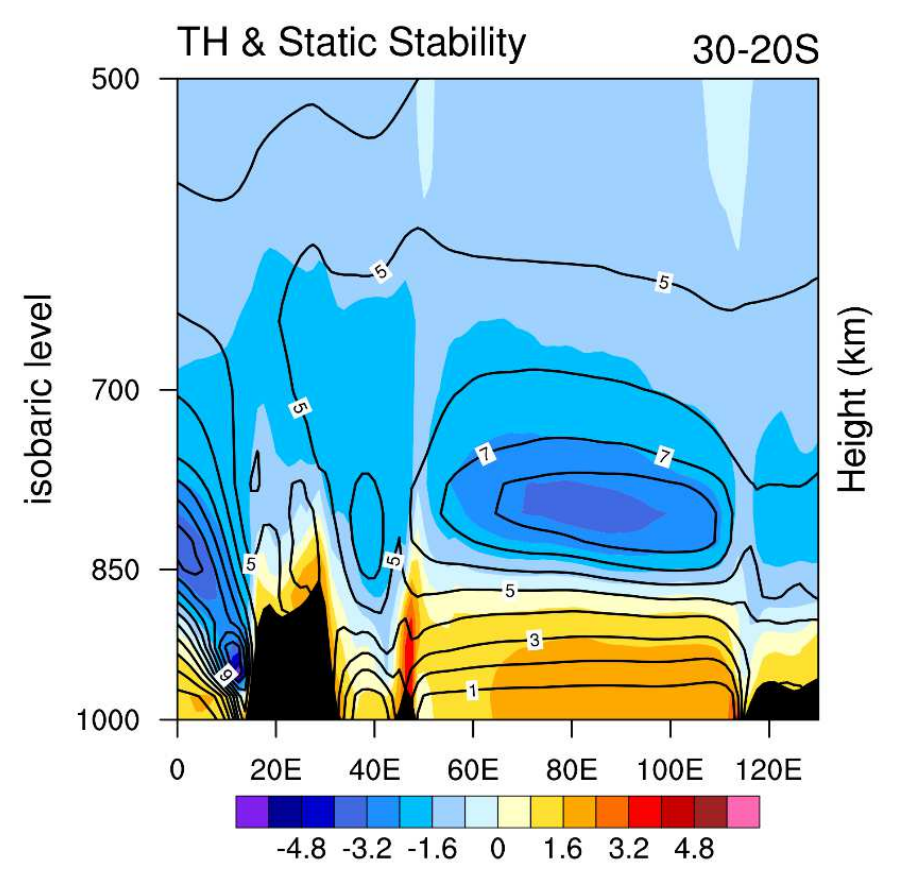

854 Fig. 10 Zonal-vertical section of distributions of total heating rate (shading; units: K day $^{-1}$ ) and static stability (contours; interval: $10^{-3} \mathrm{~K} \mathrm{~m}^{-1}$ ) averaged over $30^{\circ} \mathrm{S}-$ $20^{\circ} \mathrm{S}$. 


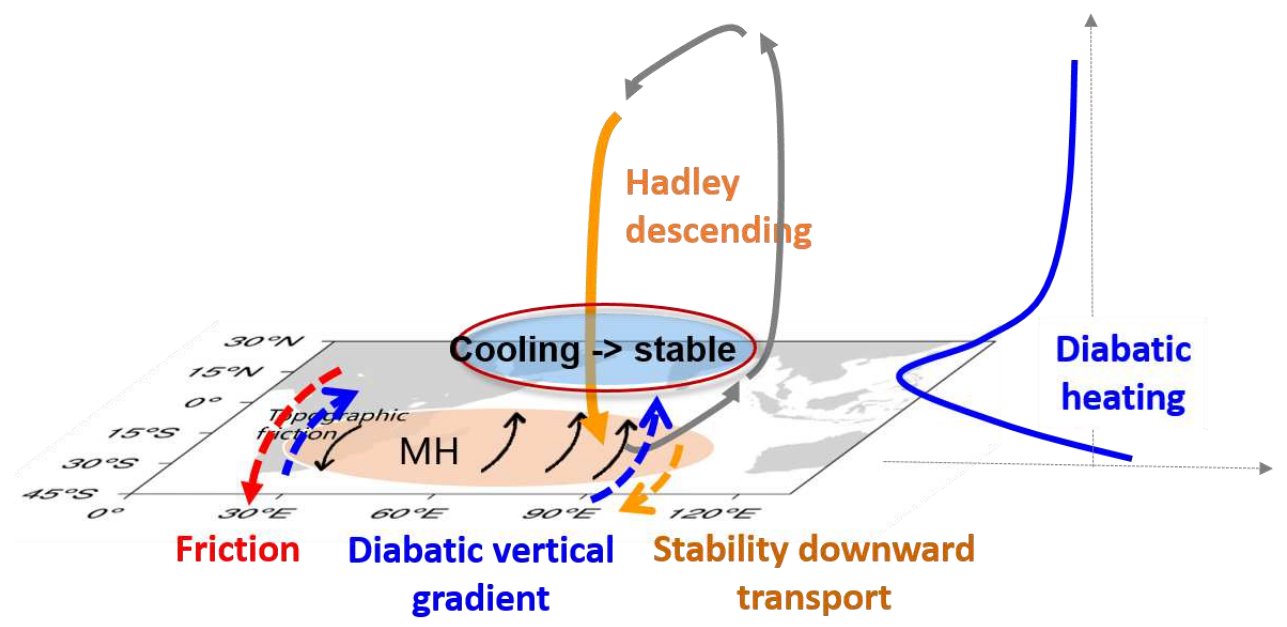

858 Fig. 11 Schematic diagram showing the maintenance mechanisms of the anticyclonic structure of the MH. The solid blue denotes the vertical profile of diabatic heating over the key region. Dashed arrows in red, blue, and orange represent the effect of frictional dissipation, the vertical gradient of diabatic heating, and the change in static stability on the maintenance of meridional winds. The regions marked with the red line and the blue shading over the subtropical South Indian Ocean indicate the center of static stability and diabatic cooling, respectively. The downward orange arrow denotes descending motion associated with the monsoonal Hadley cell, which can transport higher static stability downward. 